\title{
Impact of Conservative Versus Conventional Oxygenation on Outcomes of Patients in Intensive Care Units: A Systematic Review and Meta-analysis
}

\author{
Takashi Hirase $^{1}$, Eric S. Ruff ${ }^{2}$, Iqbal Ratnani ${ }^{3}$, Salim R. Surani ${ }^{4}$ \\ 1. Orthopedics and Sports Medicine, Houston Methodist Hospital, Houston, USA 2. Plastic Surgery, University of Texas \\ Medical Branch, Galveston, USA 3. Anesthesiology and Critical Care, Houston Methodist Hospital, Houston, USA 4. \\ Internal Medicine, Texas A\&M Health Science Center, Temple, USA
}

Corresponding author: Salim R. Surani, srsurani@hotmail.com

\begin{abstract}
Background: There is mixed evidence in the superiority of conservative versus conventional approach to oxygen therapy among patients admitted into the intensive care unit (ICU). The purpose of this study was to determine if conservative versus conventional oxygenation results in a statistically significant difference in outcomes in ICU patients.
\end{abstract}

Methods: A systematic review was registered with the International Prospective Register of Systematic Reviews (PROSPERO) and performed using Preferred Reporting Items for Systematic Reviews and MetaAnalyses (PRISMA) guidelines. Inclusion criteria consisted of Level I-IV investigations of conservative versus conventional oxygenation among ICU patients. ICU mortality, 28-day mortality, in-hospital mortality, ICU length-of-stay, hospital length-of-stay, rate of new infections, and rate of new non-respiratory organ failure were compared using two-sample Z-tests using $\mathrm{p}$-value less than 0.05 .

Results: Three thousand four hundred thirty-three articles were screened. Four articles were included in the analysis. Three hundred seventy-two patients under the conservative oxygenation arm (Minimum target SpO2: 88-94\%) and 370 patients under the conventional oxygenation arm (Minimum target SpO2: 96-97\%) were analyzed. ICU mortality $(16.7 \pm 9.5 \%$ vs. $22.7 \pm 6.0 \%$; $P<0.01)$, 28 -day mortality $(34.6 \pm 26.4 \%$ vs. $41.6 \pm$ $14.6 \%$; $\mathrm{P}=0.02)$, and in-hospital mortality $(30.2 \pm 22.5 \%$ vs. $37.7 \pm 14.2 \%$; $\mathrm{P}<0.01)$ were all significantly lower in the conservative oxygenation arm versus the conventional oxygenation arm, respectively. Rate of new non-respiratory organ failure was also significantly lower in the conservative oxygenation arm $(20.0 \pm 8.5 \%$ vs. $29.7 \pm 11.7 \%$; $\mathrm{P}<0.01)$.

Conclusion: The authors conclude that conservative oxygenation therapy could result in significantly lower rates of ICU mortality, 28-day mortality, in-hospital mortality, and new-onset non-respiratory organ failure. Further randomized controlled studies that show clinical outcome improvement in multiple

Received 06/10/2019

Review began 07/08/2019 Review ended 09/10/2019 Published 09/15/2019

\section{() Copyright 2019}

Hirase et al. This is an open access article distributed under the terms of the Creative Commons Attribution License CC-BY 3.0., which permits unrestricted use, distribution, and reproduction in any medium, provided the original author and source are credited. parameters may be worthwhile to assess the true efficacy of this practice.

Categories: Pulmonology

Keywords: hyperoxia, mechanical ventilation, intensive care unit

\section{Introduction}

Oxygen supplementation is often used universally to counteract acute hypoxemia in a hospital setting. Despite the widespread strategy of providing oxygenation therapy in critically ill patients, there are currently no explicit target values for arterial oxyhemoglobin saturation $\left(\mathrm{SpO}_{2}\right)$ [1]. However, studies have demonstrated that inattentiveness to $\mathrm{SpO}_{2}$ levels while providing oxygenation therapy may lead to periods of hyperoxemia and tissue hyperoxia that may result in atelectasis, interstitial fibrosis, and tracheobronchitis through the induction of alveolar protein leakage and neutrophil infiltration [2-5]. High mortality rates and other adverse outcomes have also been associated with hyperoxemia among critically ill patients [6-9]. Despite numerous evidence of adverse effects, patients continue to experience prolonged episodes of hyperoxemia in the clinical setting [10].

Conservative oxygenation therapy to minimize harmful effects from hyperoxemia have been used successfully in patients with acute respiratory distress syndrome (ARDS) as well as in acutely ill patients [1115]. However, particularly in critically ill patients, concerns from adverse effects from hypoxemia may supersede that of hyperoxemia [16-18]. Due to such opposing risks, there are conflicting opinions and evidence on conservative versus conventional oxygenation therapy, particularly among patients in the intensive care unit (ICU). 
Current studies evaluating the outcomes of conservative versus conventional oxygenation therapy in the ICU are limited to a few prospective randomized controlled studies. Thus, the purpose of this investigation was to determine if conservative oxygenation versus conventional oxygenation results in a statistically significant difference in outcomes in ICU patients. We hypothesized that patients receiving conservative oxygenation therapy would have significantly superior outcomes compared to patients receiving conventional oxygenation therapy.

\section{Materials And Methods}

A systematic review was registered with PROSPERO on February 15, 2018 (ID: CRD42018088872). PRISMA guidelines were followed [19]. Inclusion criteria consisted of Level I-IV (via Oxford Centre for Evidence-Based Medicine [CEBM]) therapeutic studies that investigated conservative versus conventional oxygenation among ICU patients [20]. Studies that included non-ICU patients were excluded. Basic science and animal studies, cadaveric studies, expert opinions, letters to editors, and review articles were excluded. Studies published in non-English languages were not excluded but were unidentified in the medical databases. In the event of different studies with duplicate subject populations, the study with the longer follow-up, higher level of evidence, a greater number of subjects, or greater clarity of methods and results was included. The authors conducted separate searches of the following medical databases: MEDLINE, Web of Science, and Cochrane Central Register of Controlled Trials databases. Under the PROSPERO registration, similar prior systematic reviews and meta-analyses were sought, and none were identified. The searches were performed on February 16, 2018. The search terms were "conservative oxygenation", "conventional oxygenation", and "intensive care unit". The search results were reviewed for duplicates and the inclusion criteria to determine articles that were included in the final analysis (Figure 1).
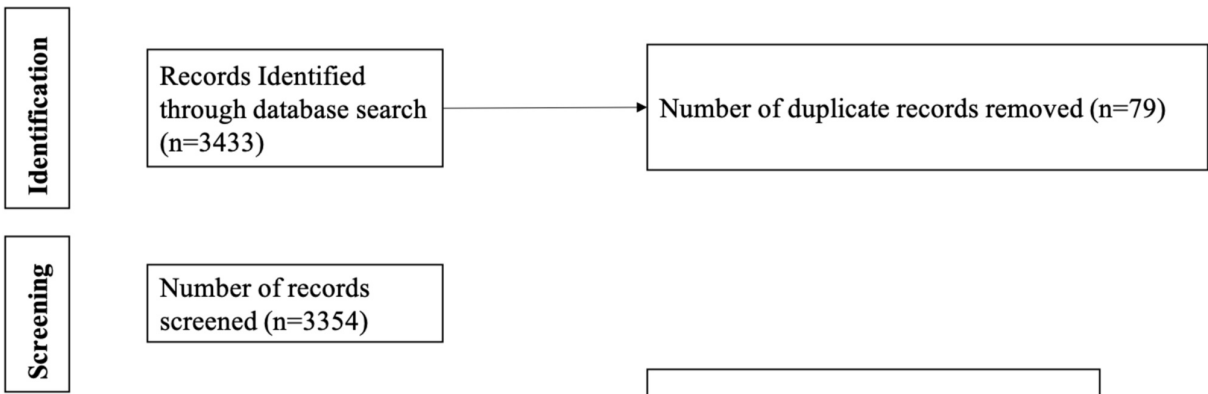

$$
\text { Number of records }
$$
screened $(n=3354)$

$$
\begin{aligned}
& \text { Number of } \\
& \text { abstracts/full text } \\
& \text { articles assessed for } \\
& \text { eligibility ( }=3354)
\end{aligned}
$$

Number of records excluded:

Basic science: 1848

Animal studies: 226

Cadaveric: 54

Letter to editor/commentary: 44

Review articles: 602

Not ICU patients: 420

Not oxygenation therapy: 156

$$
\begin{aligned}
& \text { Number of records } \\
& \text { included in final } \\
& \text { synthesis }(\mathrm{n}=4)
\end{aligned}
$$

\section{FIGURE 1: Flow diagram summarizing the literature search, screening,} and review

Two authors independently reviewed all articles. The study design, patient populations, and intervention technique were first identified. All outcome measures and complication rates were analyzed. The levels of evidence were then assigned based on the CEBM [20]. The Modified Coleman Methodology Score (MCMS) was used to analyze study methodological quality [21]. Only the outcome measurements used by more than $50 \%$ of the studies were included in the data analysis to increase the power of the measurement over that of individual studies. Weighted means of values under conservative and conventional oxygenation arms from each study were calculated, and comparisons were made using two-sample Z-tests using a p-value of less than 0.05 for significance. ICU mortality, 28-day mortality, in-hospital mortality, ICU length-of-stay, hospital length-of-stay, rate of new infections, and rate of new non-respiratory organ failure were compared. Conservative oxygenation was defined as a minimum SpO2 target of $88-94 \%$. Conventional oxygenation was defined as a minimum SpO2 target of 96-97\%.

\section{Results}

Three thousand four hundred thirty-three articles were screened (Figure 1). Four articles were included in the analysis (Table 1) [22-25]. All four articles were level II evidence. According to MCMS, all four articles 


\section{Cureus}

were good (scores between 70 and 84 ) [21]. The mean MCMS was $81.5 \pm 1.9$. There were 742 patients analyzed. Three hundred seventy-two patients were under the conservative oxygenation arm (Minimum target SpO2: 88-94\%) and 370 patients under the conventional oxygenation arm (Minimum target SpO2: 9697\%). Two hundred and fourteen males and 158 females were under the conservative oxygenation arm, and 230 males and 140 females were under the conventional oxygenation arm $(\mathrm{P}=0.20)$. The mean ages were 62.2 \pm 3.9 years and $64.1 \pm 3.5$ years under the conservative and conventional oxygenation arms, respectively (P<0.01). The mean Acute Physiology and Chronic Health Evaluation (APACHE) III scores were $86.7 \pm 30.3$ and $87.4 \pm 32.4$ under the conservative and conventional oxygenation arms, respectively $(\mathrm{P}=0.85)$. Two hundred ninety-nine patients (80.4\%) under the conservative oxygenation arm and 300 patients (81.1\%) under the conventional oxygenation arms were mechanically ventilated at the initiation of each study $(\mathrm{P}=0.81)$.

\begin{tabular}{|c|c|c|c|c|c|c|}
\hline Study & Suzuki et al. 2014 [24] & Panwar et al. 2015 [22] & Girardis et al. 2016 [25] & $\begin{array}{l}\text { Eastwood et al. } \\
2016 \text { [23] }\end{array}$ & $\begin{array}{l}\text { Weighted } \\
\text { mean, SD }\end{array}$ & $\begin{array}{l}P \text { - } \\
\text { value }\end{array}$ \\
\hline Type of Study & $\begin{array}{l}\text { Prospective, randomized } \\
\text { controlled study }\end{array}$ & $\begin{array}{l}\text { Prospective, randomized } \\
\text { controlled study }\end{array}$ & $\begin{array}{l}\text { Prospective, randomized } \\
\text { controlled study }\end{array}$ & $\begin{array}{l}\text { Prospective, } \\
\text { randomized } \\
\text { controlled study }\end{array}$ & N/A & N/A \\
\hline $\begin{array}{l}\text { Level of } \\
\text { Evidence }\end{array}$ & II & II & II & II & N/A & N/A \\
\hline $\begin{array}{l}\text { Included } \\
\text { Patients }\end{array}$ & $\begin{array}{l}\text { Age } \geq 18 \text { admitted to ICU } \\
\text { on MV with expected MV } \\
\text { time } \geq 48 \text { hours }\end{array}$ & $\begin{array}{l}\text { Age } \geq 18 \text { admitted to ICU } \\
\text { on } M V \text { with expected MV } \\
\text { time } \geq 24 \text { hours }\end{array}$ & $\begin{array}{l}\text { Age } \geq 18 \text { admitted to ICU } \\
\text { with expected ICU LOS } \geq \\
72 \text { hours }\end{array}$ & $\begin{array}{l}\text { Age } \geq 18 \\
\text { admitted to ICU } \\
\text { on } \mathrm{MV} \text { post } \mathrm{CA}\end{array}$ & & \\
\hline \multicolumn{7}{|c|}{$\mathrm{SpO}_{2}$ Minimum Target } \\
\hline Conservative & $90 \%$ & $88 \%$ & $94 \%$ & $88 \%$ & $91.8 \pm 2.8$ & $<$ \\
\hline Conventional & $97 \%$ & $96 \%$ & $97 \%$ & $97 \%$ & $96.9 \pm 0.5$ & 0.01 \\
\hline \multicolumn{7}{|l|}{ No. patients } \\
\hline Conservative & 54 & 52 & 216 & 50 & $\begin{array}{l}147.2 \pm \\
82.0\end{array}$ & \multirow{2}{*}{0.73} \\
\hline Conventional & 51 & 51 & 218 & 50 & $\begin{array}{l}149.3 \pm \\
83.7\end{array}$ & \\
\hline \multicolumn{7}{|l|}{ Age, SD (IQR) } \\
\hline Conservative & $56 \pm 16$ & $62.4 \pm 14.9$ & $63(51-74)$ & $65(59-77)$ & $62.2 \pm 3.9$ & \multirow{2}{*}{$\begin{array}{l}< \\
0.01\end{array}$} \\
\hline Conventional & $59 \pm 17$ & $62.4 \pm 17.4$ & $65(52-76)$ & $67(50-71)$ & $64.1 \pm 3.5$ & \\
\hline \multicolumn{7}{|l|}{ Female gender (\%) } \\
\hline Conservative & $22(40.7 \%)$ & $20(38.5 \%)$ & 95 (44.0\%) & $21(42.0 \%)$ & $42.5 \%$ & \multirow{2}{*}{0.20} \\
\hline Conventional & $13(25.5 \%)$ & $18(35.3 \%)$ & $93(42.7 \%)$ & $16(32.0 \%)$ & $37.8 \%$ & \\
\hline \multicolumn{7}{|c|}{ Mechanical Ventilation N, (\%) } \\
\hline Conservative & $54(100 \%)$ & $52(100 \%)$ & $143(66.2 \%)$ & $50(100 \%)$ & $80.4 \%$ & \multirow{2}{*}{0.81} \\
\hline Conventional & $51(100 \%)$ & $51(100 \%)$ & 148 (67.9\%) & $50(100 \%)$ & $81.1 \%$ & \\
\hline \multicolumn{7}{|c|}{ APACHE III score (IQR) } \\
\hline Conservative & $62(49-92)$ & $79.5(61-92.5)$ & NR & 121 (105-142) & $\begin{array}{l}86.7 \pm \\
30.3\end{array}$ & \multirow{2}{*}{0.85} \\
\hline Conventional & $68(42-94)$ & $70(50-84)$ & NR & $125(107-141)$ & $\begin{array}{l}97.4 \pm \\
32.35\end{array}$ & \\
\hline
\end{tabular}

\section{TABLE 1: Study demographics.}

NR-Not recorded, APACHE-Acute Physiology and Chronic Health Evaluation, LOS-length of stay, MV-mechanical ventilation, CA-cardiac arrest 


\section{Cureus}

ICU mortality ( $16.7 \pm 9.5 \%$ vs. $22.7 \pm 6.0 \%$; $<0.01), 28$-day mortality ( $34.6 \pm 26.4 \%$ vs. $41.6 \pm 14.6 \% ; \mathrm{P}=0.02$ ), and in-hospital mortality ( $30.2 \pm 22.5 \%$ vs. $37.7 \pm 14.2 \%$; $<<0.01)$ were all significantly lower in the conservative oxygenation arm versus the conventional oxygenation arm, respectively (Tables 2, 3). Rate of new non-respiratory organ failure was also significantly lower in the conservative oxygenation arm (20.0 \pm $8.5 \%$ vs. $29.7 \pm 11.7 \% ; \mathrm{P}<0.01)$. There were no significant differences in ICU LOS $(6.2 \pm 2.5$ days vs. $6.0 \pm 1.0$ days; $\mathrm{P}=0.19)$, hospital $\operatorname{LOS}(18.9 \pm 6.7$ days vs. $18.3 \pm 6.0$ days; $\mathrm{P}=0.23)$ and new onset infections ( $26.0 \pm$ $27.8 \%$ vs. $29.0 \pm 22.6 \% ; \mathrm{P}=0.17$ ) between conservative and conventional oxygenation arms, respectively.

\begin{tabular}{|c|c|c|c|c|}
\hline Study & Suzuki et al. 2014 [24] & Panwar et al. 2015 [22] & Girardis et al. 2016 [25] & Eastwood et al. 2016 [23] \\
\hline \multicolumn{5}{|l|}{ ICU Mortality, N (\%) } \\
\hline Conservative & NR & $13(25 \%)$ & $25(11.6 \%)$ & $15(30 \%)$ \\
\hline Conventional & NR & $12(24 \%)$ & $44(20.2 \%)$ & $16(32 \%)$ \\
\hline \multicolumn{5}{|c|}{$28-\mathrm{d}$ mortality, $\mathrm{N}(\%)$} \\
\hline Conservative & $9(16.7 \%)$ & NR & NR & $27(54 \%)$ \\
\hline Conventional & $16(31.4 \%)$ & NR & NR & $26(52 \%)$ \\
\hline \multicolumn{5}{|c|}{ Hospital mortality, N (\%) } \\
\hline Conservative & NR & NR & $52(24.2 \%)$ & $28(56 \%)$ \\
\hline Conventional & NR & NR & 74 (33.9\%) & 27 (54\%) \\
\hline \multicolumn{5}{|c|}{ ICU LOS, Days (IQR) } \\
\hline Conservative & NR & $9(5-13)$ & $6(4-10)$ & $4(2-7)$ \\
\hline Conventional & $N R$ & $7(4-12)$ & $6(4-11)$ & $5(4-9)$ \\
\hline \multicolumn{5}{|c|}{ Hospital LOS, Days (IQR) } \\
\hline Conservative & NR & $20(10-25)$ & $21(13-38)$ & $9(3-17)$ \\
\hline Conventional & NR & $16(7-30)$ & $21(12-34)$ & $9(4-24)$ \\
\hline \multicolumn{5}{|c|}{ New infections, $\mathrm{N}(\%)$} \\
\hline Conservative & $31(57.4)$ & NR & $39(18.1)$ & NR \\
\hline Conventional & $28(54.9)$ & NR & $50(22.9)$ & NR \\
\hline \multicolumn{5}{|c|}{ New non-respiratory organ failure, $\mathrm{N}(\%)$} \\
\hline Conservative & $16(29.6)$ & NR & 38 (17.6) & NR \\
\hline Conventional & $22(43.1)$ & NR & $58(26.6)$ & NR \\
\hline
\end{tabular}

\section{TABLE 2: Individual Study Outcomes Measures.}

NR-Not recorded, ICU-intensive care unit, LOS-length-of-stay 


\section{Cureus}

\begin{tabular}{|c|c|c|c|c|c|c|c|}
\hline & $\begin{array}{l}\text { ICU } \\
\text { Mortality } \\
(\%)\end{array}$ & $\begin{array}{l}\text { 28-day } \\
\text { Mortality (\%) }\end{array}$ & $\begin{array}{l}\text { In-hospital } \\
\text { Mortality (\%) }\end{array}$ & $\begin{array}{l}\text { ICULOS } \\
\text { (Days) }\end{array}$ & $\begin{array}{l}\text { Hospital LOS } \\
\text { (Days) }\end{array}$ & $\begin{array}{l}\text { New } \\
\text { Infections } \\
(\%)\end{array}$ & $\begin{array}{l}\text { New non-respiratory organ } \\
\text { failure (\%) }\end{array}$ \\
\hline Conservative & $16.7 \pm 9.5$ & $34.6 \pm 26.4$ & $30.2 \pm 22.5$ & $6.2 \pm 2.5$ & $18.9 \pm 6.7$ & $26.0 \pm 27.8$ & $20.0 \pm 8.5$ \\
\hline Conventional & $22.7 \pm 6.0$ & $41.6 \pm 14.6$ & $37.7 \pm 14.2$ & $6.0 \pm 1.0$ & $18.3 \pm 6.0$ & $29.0 \pm 22.6$ & $29.7 \pm 11.7$ \\
\hline P-value & $<0.01$ & 0.02 & $<0.01$ & 0.19 & 0.23 & 0.17 & $<0.01$ \\
\hline
\end{tabular}

TABLE 3: Average Study Outcome Measures Included in Best Evidence Synthesis.

ICU-intensive care unit, LOS-length of stay

\section{Discussion}

We determined that conservative oxygenation therapy among ICU patients resulted in significantly lower ICU mortality, 28-day mortality, in-hospital mortality, and new-onset non-respiratory organ failure compared to conventional oxygenation therapy. This supports our hypothesis that patients receiving conservative oxygenation therapy result in significantly superior outcomes compared to patients receiving conventional oxygenation therapy. To our knowledge, this is the first systematic review and meta-analysis to evaluate the outcomes of conservative versus conventional oxygenation therapies, specifically among ICU patients.

Suzuki et al. and Girardis et al. were among the analyzed studies that found that conservative oxygenation therapy resulted in lower onset of new infections and non-respiratory organ failure [24,25]. However, there was no statistical difference in the onset of infections after combining the data. On the other hand, conservative oxygenation therapy resulted in significantly lower onset of non-respiratory organ failure. Studies have shown that hyperoxemia reduces systemic oxygen delivery, cerebral blood flow, and cardiac output, while simultaneously increasing reactive oxygen species leading to oxidative stress. These pieces of evidence may explain the results observed in the investigation of non-respiratory organ failure [26-28].

The higher prevalence for hypoxemia among mechanically ventilated patients may be a postulated concern for worse outcomes with conservative oxygenation. However, this investigation with a similar proportion of mechanically ventilated and non-ventilated patients demonstrated better outcomes among patients receiving conservative oxygenation. This may be explained by a higher risk of developing hyperoxia-induced pulmonary toxicity, which has been associated with higher mortality and worse outcomes, particularly among mechanically ventilated patients $[29,30]$.

There are several limitations among the studies included in the review. None of the studies were blinded, causing possible interviewer bias. The heterogeneity of outcome measures used among the studies limited the data analysis to seven outcome measures. Furthermore, there was a slight heterogeneity of SpO2 targets in each study, producing potential bias. The APACHE III scores of the studied patients were also not reported in the study by Girardis et al. Moreover, patients under the conservative oxygenation arm were slightly younger $(62.2 \pm 3.9$ years vs. $64.1 \pm 3.5$ years $)$ compared to patients under the conventional oxygenation arm. Potential differences in the APACHE III score, as well as age differences, may thus be partially responsible for the observed differences in outcomes. Another possible limitation of this review is that other relevant studies on this topic could have been excluded, despite conducting a systematic search. Future studies can improve through increasing study size and standardizing clinical outcome measures simultaneously.

\section{Conclusions}

In conclusion, conservative oxygenation therapy could result in significantly lower rates of ICU mortality, 28-day mortality, in-hospital mortality, and new-onset non-respiratory organ failure. Further randomized controlled studies that show clinical outcome improvement in multiple parameters may be worthwhile to assess the true efficacy of this practice.

\section{Additional Information}

\section{Disclosures}

Human subjects: All authors have confirmed that this study did not involve human participants or tissue. Animal subjects: All authors have confirmed that this study did not involve animal subjects or tissue. Conflicts of interest: In compliance with the ICMJE uniform disclosure form, all authors declare the following: Payment/services info: All authors have declared that no financial support was received from any organization for the submitted work. Financial relationships: All authors have declared that they have 
no financial relationships at present or within the previous three years with any organizations that might have an interest in the submitted work. Other relationships: All authors have declared that there are no other relationships or activities that could appear to have influenced the submitted work.

\section{References}

1. Martin DS, Grocott MP: Oxygen therapy in critical illness: precise control of arterial oxygenation and permissive hypoxemia. Crit Care Med. 2013, 41:423-432. 10.1097/CCM.0b013e31826a44f6

2. Davis WB, Rennard SI, Bitterman PB, Crystal RG: Pulmonary oxygen toxicity: early reversible changes in human alveolar structures induced by hyperoxia. N Engl J Med. 1983, 309:878-883. 10.1056/NEJM198310133091502

3. Jackson RM: Pulmonary oxygen toxicity. Chest. 1985, 88:900-905. 10.1378/chest.88.6.900

4. Fracica PJ, Knapp MJ, Piantadosi CA, et al.: Responses of baboons to prolonged hyperoxia: physiology and qualitative pathology. J Appl Physiol. 1991, 71:2352-2362. 10.1152/jappl.1991.71.6.2352

5. Crapo JD: Morphologic changes in pulmonary oxygen toxicity. Annu Rev Physiol. 1986, 45:721-731. 10.1146/annurev.ph.48.030186.003445

6. Austin MA, Wills KE, Blizzard L, Walters EH, Wood-Baker R: Effect of high flow oxygen on mortality in chronic obstructive pulmonary disease patients in prehospital setting: randomised controlled trial. BMJ. 2010, 341:c5462. 10.1136/bmj.c5462

7. Meyhoff CS, Jorgensen LN, Wetterslev J, Christensen KB, Rasmussen LS: Increased long-term mortality after a high perioperative inspiratory oxygen fraction during abdominal surgery: follow-up of a randomized clinical trial. Anesth Analg. 2012, 115:849-854. 10.1213/ANE.0b013e3182652a51

8. Kilgannon JH, Jones AE, Shapiro NI, et al.: Association between arterial hyperoxia following resuscitation from cardiac arrest and in-hospital mortality. JAMA. 2010, 303:2165-2171. 10.1001/jama.2010.707

9. de Jonge E, Peelen L, Keijzers PJ, et al.: Association between administered oxygen, arterial partial oxygen pressure and mortality in mechanically ventilated intensive care unit patients. Crit Care. 2008, 12:R156. $10.1186 /$ cc7150

10. Suzuki S, Eastwood GM, Peck L, Glassford MJ, Bellomo R: Current oxygen management in mechanically ventilated patients: a prospective observational cohort study. J Crit Care. 2013, 28:647-654. 10.1016/j.jcrc.2013.03.010

11. The Acute Respiratory Distress Syndrome Network, Brower RG, Matthay MA, Morris A, Schoenfeld D, Thompson BT, Wheeler A.: Ventilation with lower tidal volumes as compared with traditional tidal volumes for acute lung injury and the acute respiratory distress syndrome. N Engl J Med. 2000, 342:1301-1308. 10.1056/NEJM200005043421801

12. Meade MO, Cook DJ, Guyatt GH, et al.: Ventilation strategy using low tidal volumes, recruitment maneuvers, and high positive end-expiratory pressure for acute lung injury and acute respiratory distress syndrome: a randomized controlled trial. JAMA. 2008, 299:637-645. 10.1001/jama.299.6.637

13. Mercat A, Richard JC, Vielle B, et al.: Positive end-expiratory pressure setting in adults with acute lung injury and acute respiratory distress syndrome: a randomized controlled trial. JAMA. 2008, 299:646-655. 10.1001/jama.299.6.646

14. O'Driscoll BR, Howard LS, Davison AG: BTS guideline for emergency oxygen use in adult patients . Thorax. 2008, 63:vi1-68. 10.1136/thx.2008.102947

15. Slutsky AS: Consensus conference on mechanical ventilation-January 28-30, 1993 at Northbrook, Illinois, USA. Part I. Intensive Care Med. 1994, 20:64-79. 10.1007/BF0242506

16. Wang $\mathrm{CH}$, Chang WT, Huang $\mathrm{CH}$, et al.: The effect of hyperoxia on survival following adult cardiac arrest: a systematic review and meta-analysis of observational studies. Resuscitation. 2014, 85:1142-8. 10.1016/j.resuscitation.2014.05.021

17. Eastwood G, Bellomo R, Bailey M, et al.: Arterial oxygen tension and outcome in mechanically ventilated patients. Intens Care Med. 2012, 38:91-8. 10.1007/s00134-011-2419-6

18. Ihle JF, Bernard S, Bailey MJ, Pilcher DV, Smith K, Scheinkestel CD: Hyperoxia in the intensive care unit and outcome after out-of-hospital ventricular fibrillation cardiac arrest. Crit Care Resusc. 2013, 1:186-90.

19. Moher D, Liberati A, Tetzlaff J, Altman DG; PRISMA Group: Preferred reporting items for systematic reviews and meta-analyses: the PRISMA statement. PLoS Med. 2009, 6:e100097. 10.1371/journal.pmed.1000097

20. The 2011 Oxford CEBM evidence levels of evidence (introductory document) . (2011). https://www.cebm.net/2011/06/2011-oxford-cebm-levels-evidence-introductory-document/.

21. Coleman BD, Khan KM, Maffulli N, Cook JL, Wark JD: Studies of surgical outcome after patellar tendinopathy: clinical significance of methodological deficiencies and guidelines for future studies.. Scand I Med Sci Sports. 2000, 10:2-11. 10.1034/j.1600-0838.2000.010001002.x

22. Panwar R, Hardie M, Bellomo R, et al.: Conservative versus liberal oxygenation targets for mechanically ventilated patients. A pilot multicenter randomized controlled trial. Am J Respir Crit Care Med. 2016, 193:43-51. 10.1164/rccm.201505-10190C

23. Eastwood GM, Tanaka A, Espinoza ED, et al.: Conservative oxygen therapy in mechanically ventilated patients following cardiac arrest: a retrospective nested cohort study. Resuscitation. 2016, 101:108-14. 10.1016/j.resuscitation.2015.11.026

24. Suzuki S, Eastwood GM, Glassford NJ, et al.: Conservative oxygen therapy in mechanically ventilated patients: a pilot before-and-after trial. Crit Care Med. 2014, 42:1414-22. 10.1097/CCM.0000000000000219

25. Girardis M, Busani S, Damiani E, et al.: Effect of conservative vs conventional oxygen therapy on mortality among patients in an intensive care unit: the oxygen-ICU randomized clinical trial. JAMA. 2016, 18:1583-9. 10.1001/jama.2016.11993

26. Bodetoft S, Carlsson M, Arheden H, Ekelund U: Effects of oxygen inhalation on cardiac output, coronary blood flow and oxygen delivery in healthy individuals, assessed with MRI. Eur J Emerg Med. 2011, 18:25-30. 10.1097/MEJ.0b013e32833a295e

27. Wagner M, Magerkurth J, Volz S, et al.: T2'-and PASL-based perfusion mapping at 3 Tesla: Influence of 


\section{Cureus}

oxygen-ventilation on cerebral autoregulation. J Magn Reson Imaging. 2012, 36:1347-1352.

10.1002/jmri.23777

28. Brerr-Saby C, Delliaux S, Steinberg JG, Jammes Y: The changes in neuromuscular excitability with normobaric hyperoxia in humans. Exp Physiol. 2010, 95:153-159. 10.1113/expphysiol.2009.049460

29. Kiers D, Gerretsen J, Janssen E, et al.: Short-term hyperoxia does not exert immunologic effects during experimental murine and human endotoxemia. Sci. Rep. 2015, 5:17441. 10.1038/srep17441

30. Sinclair SE, Altemeier WA, Matute-Bello G, Chi EY: Augmented lung injury due to interaction between hyperoxia and mechanical ventilation. Crit Care Med. 2004, 32:2496-2501.

10.1097/01.CCM.0000148231.04642.8D 